\title{
Diverting Municipal Solid Waste from landfill: new methods in Hungarian waste management
}

\author{
A. Sarkady ${ }^{1}$, R. Kurdi ${ }^{1}$, B. Morvai ${ }^{2}$ \& C. Leitol $^{3}$ \\ ${ }^{1}$ University of Pannonia, \\ Institute of Environmental Engineering, Hungary \\ ${ }^{2}$ University of Pannonia, Project Office, Hungary \\ ${ }^{3}$ University of Pécs, Department of Environmental Engineering, Hungary
}

\begin{abstract}
Facing the new challenge in Hungary to meet the EU legislation diverting waste stream from the landfill is inevitable. Low-waste design products and reuse are preferred, although recycling and recovery are also necessary to reach the ambitious goal of waste management. Besides finding new methods for recycling materials from Mixed Municipal Solid Waste (MSW), it is beneficial to make use of an appropriate fraction as an energy source for industry and for power generation. To reach the end-of-waste status of MSW, special standard requirements must be met by special processes. Standardisation processes also assist customers to develop their technology to be prepared for the new type of fuel transformed from waste, by setting up limits and giving specifications. In this way, Refuse Derived Fuel (RDF) or Solid Recovered Fuel (SRF) can be introduced to various technologies as a replacement for non-renewable fuel, especially for the cement industry and power plants.
\end{abstract}

Keywords: mechanical biological treatment, Refuse Derived Fuel, Solid Recovered Fuel.

\section{Introduction}

The amount of Municipal Solid Waste (MSW) has been increased by $9 \%$ - from 226 million ton (1995) to 247 million ton (2012) - in the member states of the European Union. According to EU statistical data [1], a significant shift in the rate of the waste handling can be witnessed. The amount of the landfill has dropped by $43 \%$, whilst the recycling grew by $162 \%$, the composting by $142 \%$ and the incineration by $81 \%$. For details see Table 1. 
Table 1: Handled waste amount from methods used in 1995-2012 by the EU 27.

\begin{tabular}{|c|c|c|c|c|c|c|c|c|c|c|c|c|c|c|c|c|c|}
\hline \multicolumn{18}{|c|}{ Municipal waste landfilled, incinerated, recycled and composted in the EU.27 } \\
\hline & & & & & & & & & & & & & & & & & change $(3)$ \\
\hline & 1995 & 1996 & 1997 & 1998 & 1999 & 2000 & 2001 & 20022003 & 2004 & 2005 & 2006 & 2007 & 2008 & 2009 & 2010 & 20112012 & 1995.2012 \\
\hline \multicolumn{18}{|c|}{ million tonnes } \\
\hline Landfill & 143 & 140 & 142 & 140 & 139 & 139 & 134 & 131124 & 117 & 109 & 109 & 106 & 99 & 96 & 93 & 86 & $43 \%$ \\
\hline Incineration & 32 & 33 & 35 & 35 & 36 & 39 & 40 & $41 \quad 41$ & 44 & 48 & 51 & 52 & 55 & 56 & 57 & 60 & $81 \%$ \\
\hline Recycling & 25 & 28 & 32 & 35 & 40 & 40 & 42 & $46 \quad 47$ & 49 & 52 & 54 & 59 & 60 & 61 & 63 & 65 & $162 \%$ \\
\hline Composting & 14 & 16 & 17 & 18 & 19 & 24 & 24 & 26 & 28 & 29 & 31 & 32 & 35 & 35 & 34 & 34 & $149 \%$ \\
\hline Other & 12 & 14 & 13 & 11 & 12 & 11 & 12 & $12 \quad 12$ & 13 & 16 & 13 & 11 & 10 & 7 & 7 & 6 & $.50 \%$ \\
\hline \multicolumn{18}{|c|}{ kg per capita } \\
\hline Landfill & 300 & 294 & 297 & 290 & 289 & 288 & 278 & 269255 & 239 & 221 & 220 & 213 & 199 & 192 & 186 & $171 \quad 162$ & $46 \%$ \\
\hline Incineration & 67 & 69 & 72 & 74 & 75 & 80 & 82 & $85 \quad 85$ & 90 & 98 & 104 & 105 & 110 & 111 & 114 & $119 \quad 116$ & $72 \%$ \\
\hline Recycling & 53 & 59 & 66 & 72 & 82 & 83 & 88 & 95 & 99 & 105 & 109 & 119 & 120 & 122 & 125 & $129 \quad 132$ & $150 \%$ \\
\hline Composting & 30 & 34 & 36 & 37 & 40 & 49 & 50 & 53 & 58 & 60 & 63 & 64 & 71 & 70 & 68 & 68 & $137 \%$ \\
\hline Other & 24 & 30 & 27 & 24 & 25 & 24 & 24 & 24 & 27 & 33 & 27 & 22 & 20 & 15 & 13 & 13 & $-53 \%$ \\
\hline
\end{tabular}

The mass of MSW in Hungary has dropped by 13\% (from 4.6 million to 4 million) between 2007 and 2012. The waste handling tendencies (Table 2) in the past years shifted from waste dumping towards the recycling, while the ratio of energetic recovery has not change significantly.

Table 2: Handled waste amount from the methods used in 1995-2012 in Hungary [2].

\begin{tabular}{|l|r|r|r|r|r|r|}
\cline { 2 - 7 } \multicolumn{1}{c|}{} & \multicolumn{2}{c|}{2010} & \multicolumn{2}{c|}{2011} & \multicolumn{2}{c}{2012} \\
\hline Total waste (ton) & $\mathbf{4 0 3 3 1 0 6}$ & $100.00 \%$ & 3808878 & $100.00 \%$ & 3987496 & $100.00 \%$ \\
\hline Recycled waste (ton) & 788786 & $19.56 \%$ & 837312 & $21.98 \%$ & 1015067 & $25.46 \%$ \\
\hline Energetic recovery (ton) & $\mathbf{4 0 6 4 2 6}$ & $10.08 \%$ & 4081004 & $10.71 \%$ & 364047 & $9.13 \%$ \\
\hline
\end{tabular}

The prevention of the waste production and the waste management strategy is based on the so-called "waste hierarchy" or "waste pyramid". The most favoured solution is the prevention, but if this is not possible due to certain circumstances, reuse and recycling should be applied. Incineration or landfill is only applicable if no other possibilities are present.

EU Landfill Directive (32/1999 EC) limits the amount of the waste that can be landfilled. According to the regulation in 2016 only the 35\% of the biodegradable waste can be dumped into landfill on the basis of the 1995 data. Beside that the directive forbid the landfill without pre-treatment of the waste. Mechanical and Biological Treatment (MBT), waste based fuel production, separation of recyclable metals and biodegradation of waste under controlled conditions can be a vital alternative to lower the hazardousness and the mass of the waste. The Refuse Derived Fuel (RDF) and Solid Recovered Fuel (SFR) produced by MBT plants stands on the 4th level of the waste hierarchy and belongs to the category of the energetic use. 


\subsection{Trends in the EU}

The quantity of the fuel produced from MSW is gradually increasing in the EU member states. Unfortunately Eurostat does not contain any data about MBTs, however according the studies of Ecoprog [3] the following trends can be followed: The number of MBT plants has reached 330 and the built capacity was 33 million ton by 2011 in the EU. Continuous growth is predicted, 460 plant and 46 million ton capacity is calculated by 2015.

\subsection{RDF/SRF plants in Hungary}

In Hungary there are 6 plants operating to produce RDF with the capacity of 390.000 ton per year. In 1 of the 6 there is only mechanical, in 5 there is also biological treatment. The factual waste treatment in 2013 reached 150,000 tons. This number is waited to be as high as 260,000 tons with the 2 new plants with the production launched in 2014. There are 5 more plants under construction with a summarized capacity of 250,000 ton per year, so by the end of 2015 the total capacity can reach 640,000 ton per year that is going to give $4 \%$ of the entire such capacity of the EU.

The plant "A" producing RDF/SRF had been deployed in 2005, where only mechanical treatment take place. It has a capacity of 10,000 tonnes of waste originating to industrial selective waste collection - mainly plastic with smaller amount of paper. Due to the input the technology is rather simple. Pre-shredder separator for "heavy fraction" - shredder. The output with $22-25 \mathrm{Mj} / \mathrm{kg}$ (ar) is introduced for co-combustion in the cement industry. In the other MBT plants (B-F) MSW is treated. In this cases more sophisticated technologies are present that consist pre-shredding, metal selection, sorting by size and density, fineshredding and in some case near-infrared optical selection. "B" and "C" plant had a yearly capacity of 60,000 ton and 20,000 ton, respectively, in 2008, "D" "E" "F" had been launched in 2013 with a yearly capacity of 120,000, 150,000 and 30,000 ton, respectively.

\subsection{End-of-waste status}

The European Union in the waste framework directive (WFD 2008/98/EC) has set circumstances in under the waste derived fuels (WDF) - including RDF and SRF - can receive the end-of-waste status. Between 2011 and 2013 EU have prepared several investigation and study about the end-of-waste status for WDFs in order to develop unified criteria and procedural technology [5]. Strong opposition was witnessed from professional organizations and utilizers (cement factories, power plants) about reaching end-of-waste status of WDFs and also unified criteria system and procedural technology could not be set. In February 2014 EU committee decided to withdraw the goal of reaching end-of-waste status for WDFs from the agenda. 


\subsection{Standard for RDF/SRF}

The standardization of SRF was commenced in 2002 by the CEN Technical Committee (CEN TC 343). The first issued standard (2006) was slightly modified in 2008 and 2011. The EN 15359:2011 standard in force determines the principles of the classification of SRFs [4]. Beside the standard a series of standards of 10 regulate the sampling, and the methodology for the measurement of the moisture content, heating value, ash content, sulphur, chlorine, fluorine, bromine and trace element content.

\subsection{Negative market prices}

The price of the RDF/SRF in most of the member states of the European Union are negative, the producer of the SRF/RDF pays for the utilizers (cement factories, power plants) for the reception. The gate fee depends on the quality of the $\mathrm{RDF} / \mathrm{SRF}$. The fee is set by the heating value, ash and chlorine content of the fuel. According to the extent of the difference from the expected quality the gate fee rises. In the past 2-3 years the negative prices were gradually reducing from 70 $100 \mathrm{EUR} /$ ton to $15-20 \mathrm{EUR} / \mathrm{ton}$. The required average calorific value by the cement factories is $15 \mathrm{MJ} / \mathrm{kg}$ the total halogen content (Tx) - including chlorine cannot exceed 1\%. In this case the gate fee is zero. In case of any positive or negative deviation a mathematic formula is used to calculate the fee.

\subsection{Landfill tax}

Developments in order to enforce waste recovery and treatment requires significant additional cost and in most cases economically (not counting environmental benefits) losses are motivated by landfill tax in the member states of the EU. 10 EUR per ton landfill tax was introduced in Hungary in 2013 that is a subject of raise by 10 EUR yearly to reach 40 EUR per ton by 2016. This is unfortunately not beneficial for companies with MBT technologies as the savings cannot cover the extra cost of the MBT (30-40 EUR per ton) and the negative price of the RDF/SRF.

\section{Methodology}

\subsection{Technological processes}

Inputs and outputs of two MBT plants ("D" and "E”) was investigated in the research comparing the applied treatment technologies, analysing the effect of the differences in the technology on the differences in the distribution of the output stream and the and the qualities of the produced RDF.

In the technology marked " $\mathrm{D}$ ” the incoming MSW is shredded first then ferrous fraction is removed by permanent magnet. The waste stream is then introduced to 
a revolving sieve with a hole the size of $80 \mathrm{~mm}$, to separate high bio-content waste fraction. The remaining waste stream is separated into three fractions by density into (1) heavy, (2) mid and (3) light fraction by air separation. The heavy fraction is dumped without further treatment. From the mid and light fraction, non-ferrous metal and chlorine content materials (PVC) are removed by eddy current separator and near-infrared separator. In the last step material is shredded to reach $50 \mathrm{~mm}$ particle size. Technical layout of the MBT plat "D" is shown in Figure 1.

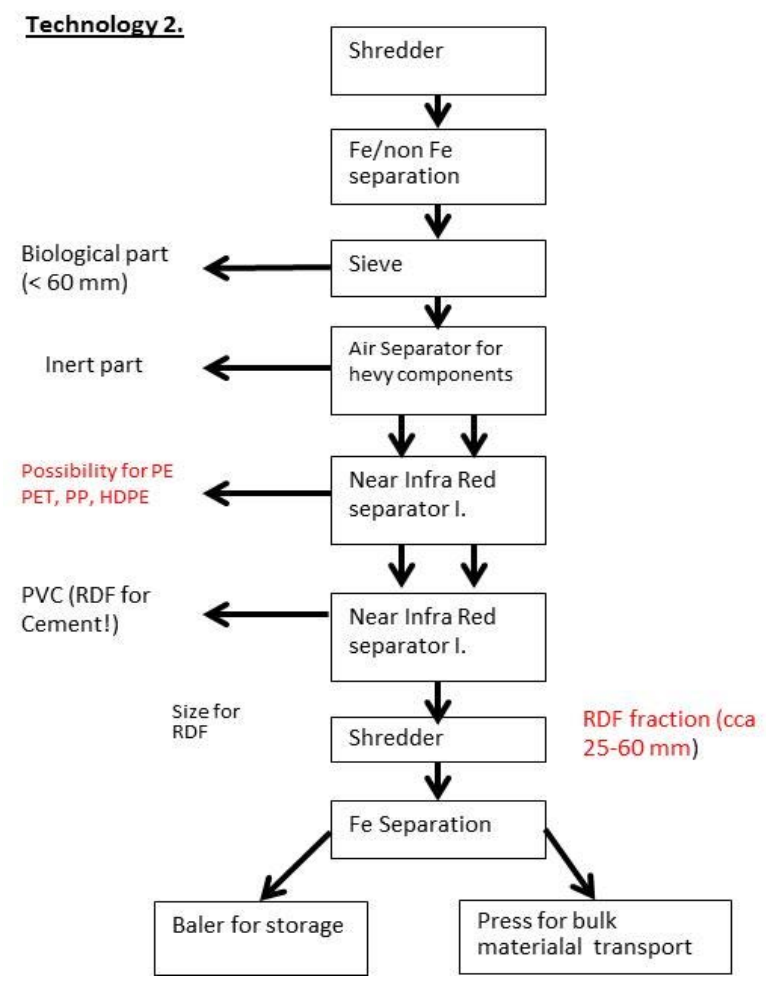

Figure 1: Flowchart of MBT plant "D”.

In the MBT technology marked "E" the input MSW is also shredded then ferrous metal fraction is removed by electrical magnet. The waste stream is then introduced to a revolving sieve with a hall size of $60 \mathrm{~mm}$, to separate high bio-content waste fraction. From the remaining waste stream non-ferrous metal is removed, then it is separated into two fraction - (1) heavy, (2) light - by air separation. The heavy fraction is dumped without further treatment. In the last step light material is shredded to reach $50 \mathrm{~mm}$ particle size and ferrous metal removal takes place. Technical layout of the MBT plat "E” is shown in Figure 2. 


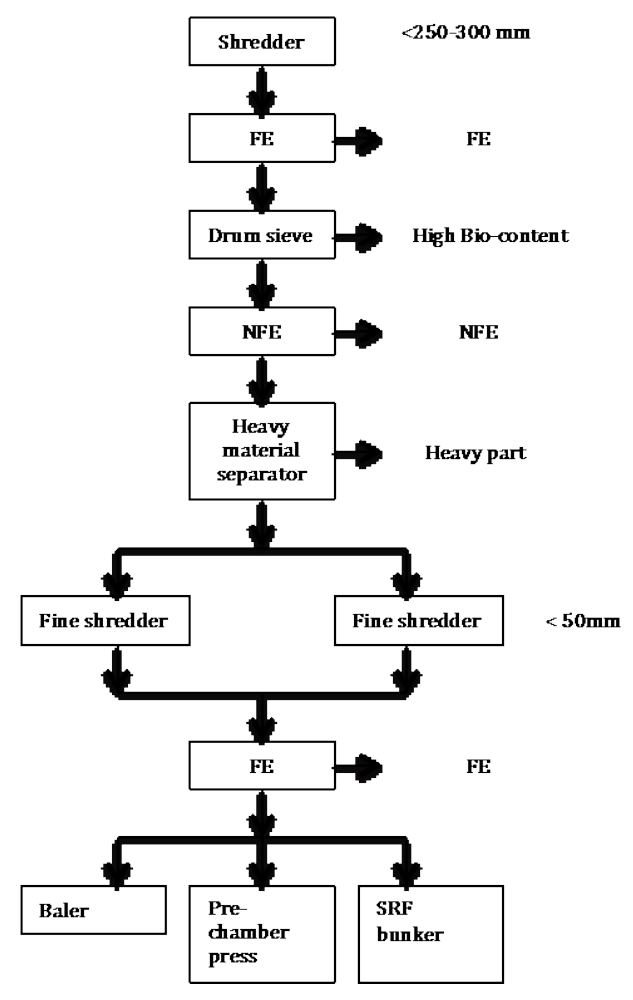

Figure 2: Flowchart of MBT plant “E”.

\subsection{Analysis of the input stream composition}

The input MSW composition had been identified separately focusing on the characteristics of the collection area (urban, suburban, and rural). Average sample were formed from the raw samples taken from different districts by separation (particle size $>100 \mathrm{~mm}$ ) and secondary separation $(100 \mathrm{~mm}>$ particle size $>20$ $\mathrm{mm}$ ) composition analysis were performed. For the correct calculation the results was weighted by the headcount ratio of the collection districts of the whole study area [7].

\subsection{Yield rates}

The input waste stream was separated in several classifications of streams. An important consideration was that how they compare to each other. For example, what portion of the input waste can be transformed into fuel? In the experimental period, the weight of each waste stream was measured and checked by weighbridge and was proportioned by the input quantity. In both MBT outputs of 
the test are as follows: (1) Fe (2) NFE, (3) high content of degradable organic fraction, (4) heavy material, and (5) RDF. The plant " $\mathrm{D}$ ” ingredients were complemented by (6) waste PVC/chlorine content categories.

\subsection{Fuel tests}

For the fuel tests daily sampling and average sampling (from daily samples) were used. To classify the RDF the European standard was applied [4]. For that classification calorific value (MJ/kg (ar)), the chlorine content (\% (d)), and mercury content (median and 80th percentile value mg/MJ (Ar)) were measured.

\section{Evaluation of data}

\subsection{Differences in the technologies}

There are three major differences in the parameters of the two technologies: (1) separation boundary of the bio fraction, (2) removal of ferrous metal, (3) removal of chlorine content plastics. The differences are summarized in Table 3.

Table 3: Differences in the technologies.

\begin{tabular}{|l|c|c|}
\hline & Plant “D” & Plant "E” \\
\hline Separation boundary of the bio fraction & $80 \mathrm{~mm}$ & $60 \mathrm{~mm}$ \\
\hline Ferrous metal removal & 1 x permanent magnet & 2 x electromagnet \\
\hline PVC (chlorine content) waste removal & optical separation (NIR) & none \\
\hline
\end{tabular}

\subsection{Input stream}

Looking at the composition of the waste can be stated that the input data between the two plants do not show a significant difference. The largest part of biodegradable waste category representing the difference between the MBT plants is less than 5\% ("D” $28.17 \%$ "E" $23.82 \%$ ). The plastic that is important regarding the fuel quality, there is only $2 \%$ difference, while there is almost no difference in paper and cardboard. There is greater difference in the unclassified combustible fraction with 2.46\% ("D”) and 5.69\% (“E”) and the particles under 20mm $6.04 \%$ ("D”) and $9.07 \%$ ("E”), although the overall effect is not significant. The comparison of the data is presented in Figure 3.

\subsection{Yield rates}

Despite the minimal differences in the input waste composition on the minimal differences in the technology there are significant differences in the yield. It is crucial to set up the right separation boundary. At the planning of technology " $E$ " deep analysis of waste were performed that consisted each residential area (city, 


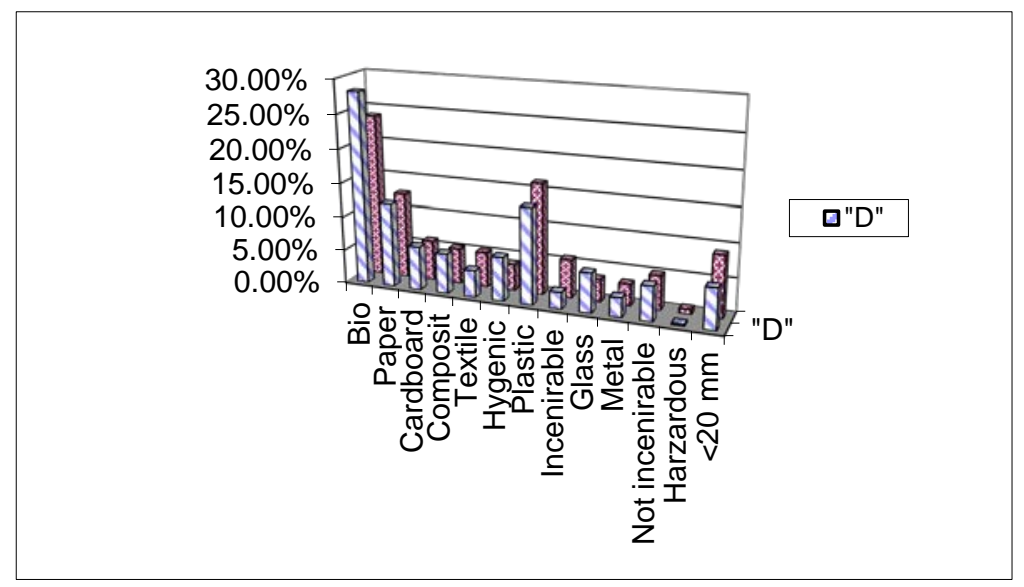

Figure 3: The composition of MSW.

suburb, housing, catchment area) and as small as $10 \mathrm{~mm}$ particle size fractions. Due to this deep analysis such separation boundary could be chosen that produces a fraction with the highest rate of biodegradable fraction beside the lowest amount of combustible components. The measurement results are shown in Figure 4 which clearly shows that over $40 \mathrm{~mm}$ the paper and the plastic limit ratio rises sharply. Above $60 \mathrm{~mm}$ grain size 25\% of paper, and 20\% plastic arrives into the bio fraction. Above $80 \mathrm{~mm}$ grain size $50 \%$ of paper and $30 \%$ of the plastic fraction falls over into the bio fraction, while the total biodegradable content raises only from $85 \%$ to $90 \%$ [8].

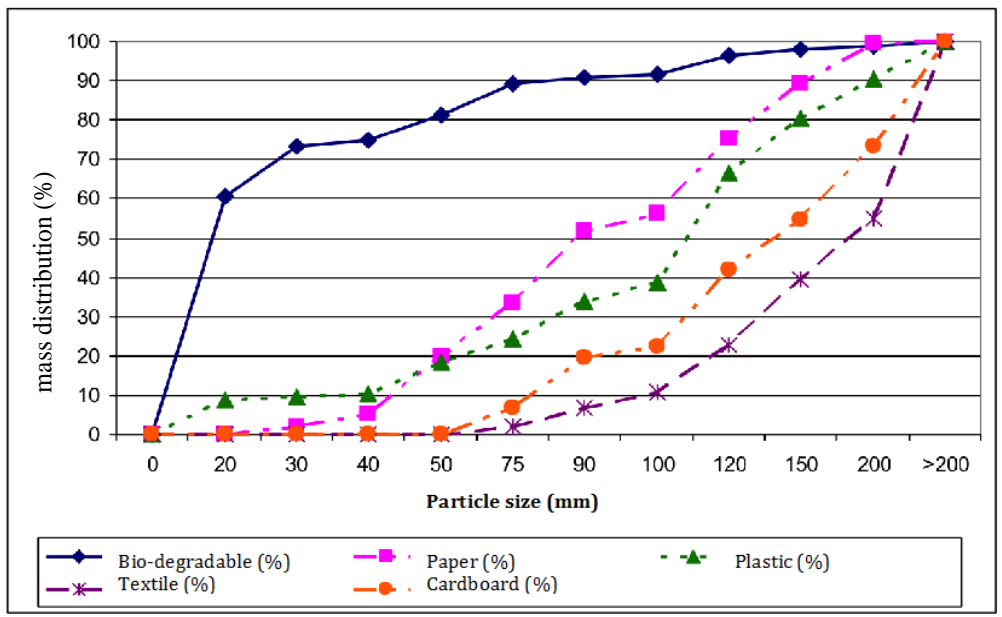

Figure 4: Mass distribution of some waste constituents as a function of particle size. 
According to Figure 3, the determined optimal solution would have been the $40 \mathrm{~mm}$ separation boundary, but according to the operational experiences of using sieve with humid MSW $60 \mathrm{~mm}$ separation boundary was chosen. Due to the differences at separation boundaries at plant " $D$ " (80 mm) and plant "E" (60mm) the separated biodegradable fraction also differs: plant “D” - 72.93\%, plant "E" $54.35 \%$. Due to this there is also an $18 \%$ difference in SRF yield that is $16.58 \%$ (“D”) and 35.29 (“E”).

Another factor affecting recovery rates the effectiveness of magnetic separation of metals. At both technology the ferrous metals removal takes places after the first shredding that affects $100 \%$ of the input. The effectiveness of the removal is insufficient due to the greater thickness of the waste on the line, multiple layers of materials, particularly due to the metals in the bottom that is impossible to remove, while the metals in the intermediate layers grabs other materials (e.g. plastics) also worsen the metal yield. There is also a difference in the magnetic device. Technology " $D$ " uses permanent magnet, technology " $E$ ” uses electromagnet that results in the separated quantity (22\% vs. $7 \%$ ). Technology "D” does not contain more ferrous metal separator, while technology "E" does an additional one after fine shredding where the fully explored material flow is handled again $(0.86 \%$, total $1.56 \%)$.

Separation of non-ferrous metals takes place after air separation in technology " $D$ " and before in technology "E”. The derived amounts are $0.12 \%$ ("D") and $0.39 \%$ ("E”)

The yield ratios of the technologies are shown in Figure 5.

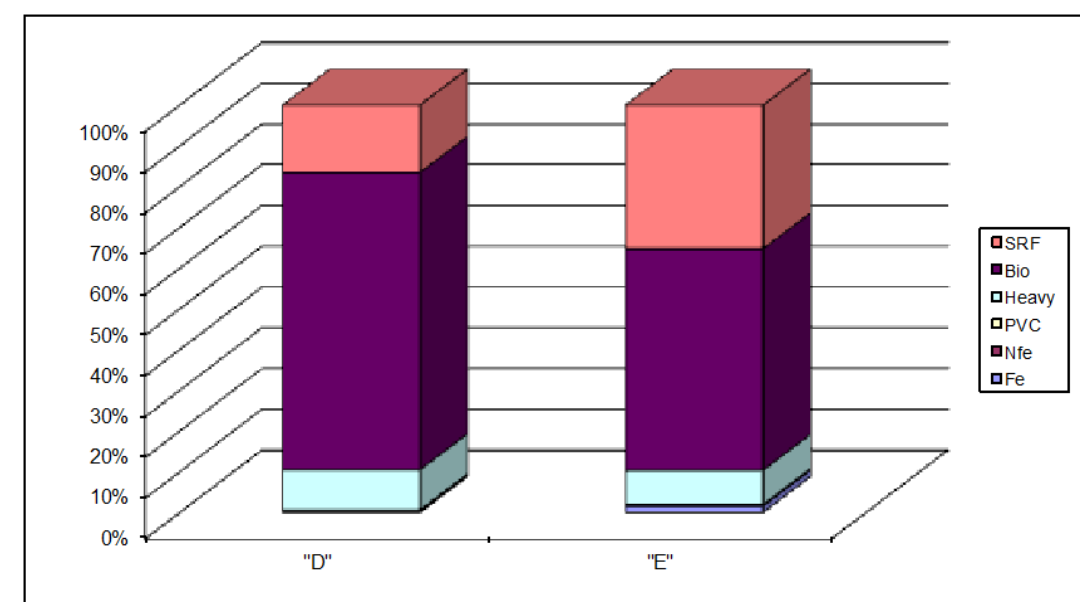

Figure 5: Yields of mechanical treatment.

\subsection{Fuel examination}

A key feature of the SRF is the calorific value. The pattern shown in Figure 6. It can be seen that SFR heating value from plant " $D$ " is higher in average with 15.13 $\mathrm{MJ} / \mathrm{kg}$ against plant “E” with $13.44 \mathrm{MJ} / \mathrm{kg}$. 


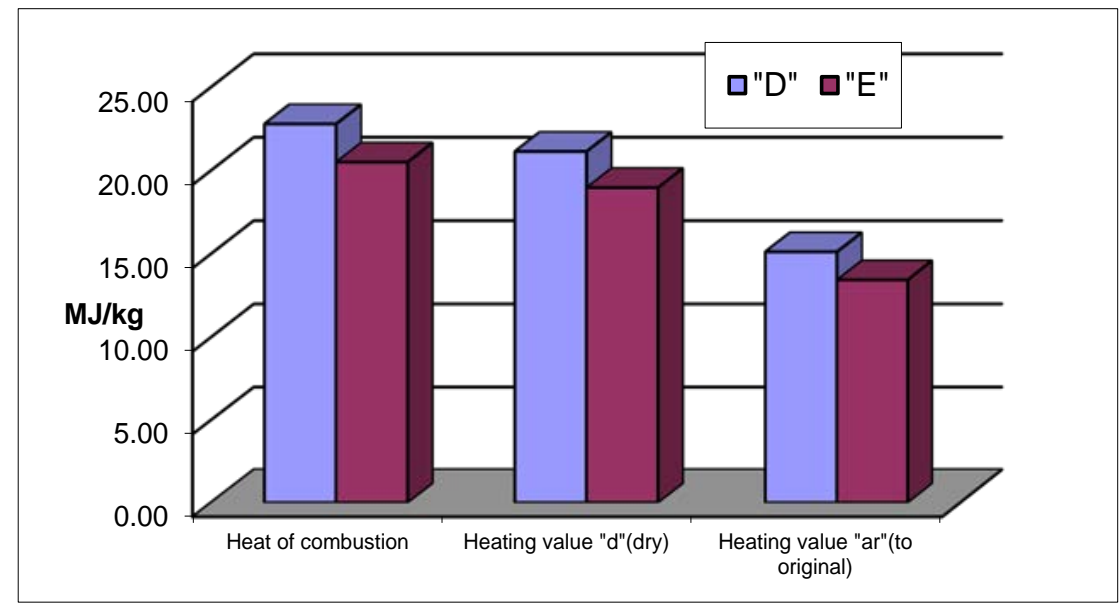

Figure 6: Changes in calorific value.

The moisture content of the SRF significantly affects the calorific value. The average moisture content is shown on Figure 7. It can be seen that the SRF at plant "E" the total moisture content is higher than at plant "D" (29.54\% vs. 28.66\%).

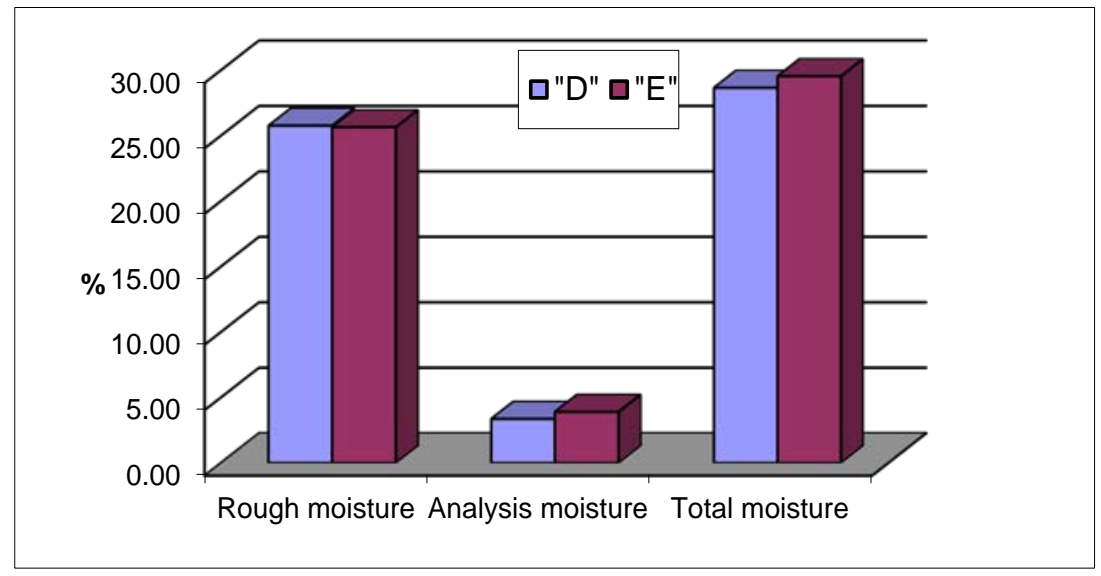

Figure 7: Changes in moisture content.

The chlorine content of 30 samples tested in 27 points for the factory " $D$ " shows lower so as better values. Crossing the $1 \%$ limit only occurs rarely. Figure 8. Illustrates the effectiveness of the optical separation by NIR separator. The ration of the separated PVC fraction is $0.28 \%$. 


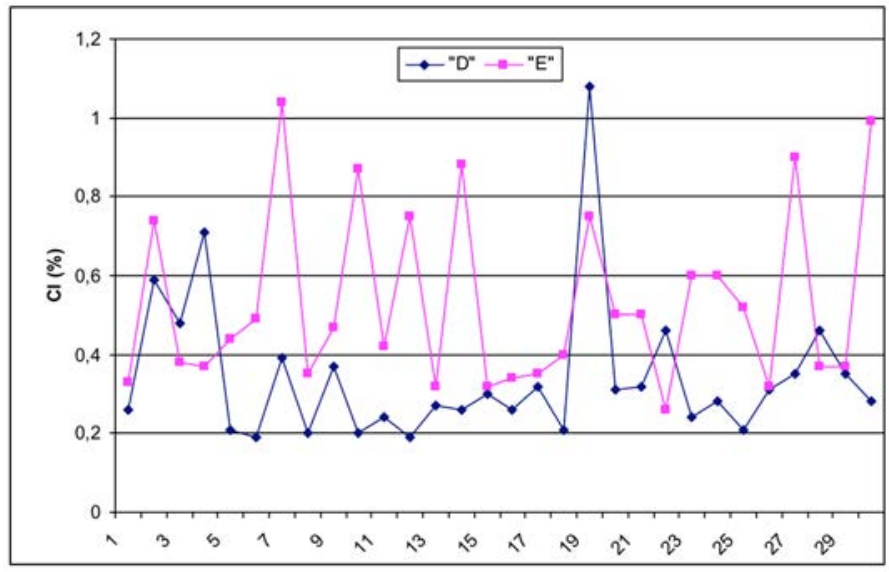

Figure 8: Development of chlorine.

\section{Findings}

Based on the results more recommendations can be given for the design of an MBT plant.

- $\quad$ Separation boundary can significantly change the yield of SRF, although it must be considered that too low level result high bio fraction rate in SRF with significantly higher moisture content that also reduces the heating value.

- $\quad$ MBT technology should be prepared for reintroduction of the materials arrived to the biodegradable fraction after biodegradation (separated by size) in order to increase the yield.

- $\quad$ At both technology moisture level were significantly high. For this reason it is necessary to focus on the separation at collection points of such bio wastes that occur high moisture.

- The careful choice of the position and number in the technology of the ferrous and non-ferrous metal removal can multiply the quantity of the separated metals.

- $\quad$ Non-ferrous metal removal should take place before the air-flow separation (density) as high portion of the non-ferrous metal arrives into the heavy fraction.

- In order to reduce the chlorine content and in this way to raise the quality the SRF NIR optical sorting machine is proposed to be used.

\section{Acknowledgements}

This work was supported by the European Union and co-financed by the European Social Fund in the frame of the TÁMOP-4.2.2.A-11/1/KONV-2012-0071 and TÁMOP-4.1.1.C-12/1/KONV-2012-0017 projects. 


\section{References}

[1] http://epp.eurostat.ec.europa.eu/statistics_explained/index.php/Municipal_w aste_statistics (last visited 12 October 2014).

[2] National Waste management Strategy http://www.szelektivinfo.hu/ (last visited 12 October 2014).

[3] Ecoprog Study The European Market for MBT Plants 2011/2012 http://www.ecoprog.com/en/publications/waste-industry/mbt.htm (last visited 12 October 2014).

[4] EN 15359:2011 Solid recovered fuels - Specifications and classes.

[5] Dr Helga Stoiber et al. Study on the suitability of the different waste-derived fuels for end-of-waste status in accordance with article 6 of the waste framework directive 2011.

http://susproc.jrc.ec.europa.eu/activities/waste/documents/EOWforwastederivedfuels_consultation_report_s.pdf

[6] Sarkady A., Kurdi R., Rédey Á. RDF - Refuse derived fuel, possibilities in the North-Balaton regional waste management system Pollack Periodica, Vol. 9. No. 3. 2014, pp. 23-30.

[7] Hungarian Standard: MSZ 21420-29:2005 analysis of Municipal Solid Waste.

[8] Dr Csőke B., Dr Bokányi L. Report to BIOKOM, March 2007. 